
\title{
3 Research Square \\ The Influence of the Femoral Condyle Sagittal Curvature on ACL Rupture
}

\section{Darko Milovanović}

University of Belgrade: Univerzitet u Beogradu

Marko Bumbaširević

University of Belgrade: Univerzitet u Beogradu

Marko Kadija

University of Belgrade: Univerzitet u Beogradu

Ninoslav Begović

University of Belgrade: Univerzitet u Beogradu

Vuk Djulejić

University of Belgrade: Univerzitet u Beogradu

Dubravka Aleksić

University of Belgrade: Univerzitet u Beogradu

Ana Starčević

University of Belgrade: Univerzitet u Beogradu

Lazar Stijak ( $\square$ lazar.stijak@gmail.com )

University of Belgrade: Univerzitet u Beogradu

https://orcid.org/0000-0003-1669-4759

\section{Research article}

Keywords: anterior cruciate ligament, femoral condyle, diameter, risk factor

Posted Date: August 30th, 2021

DOI: https://doi.org/10.21203/rs.3.rs-808872/v1

License: (c) (i) This work is licensed under a Creative Commons Attribution 4.0 International License.

Read Full License 


\section{Abstract}

Purpose: The femoral condyle diameter may influence anterior tibial translation whose main stabilizer is the ACL. The aim of this study is to determine the influence of the size of the lateral and medial femoral condyles on ACL rupture.

Methods: 41 matched pairs of subjects were included in the study who had suffered knee injury and were either professional or recreational athletes engaged in track and field or sports involving intensive rotation movements. The experimental group was composed of patients with ACL rupture, while the control group comprised patients with joint distortion without ACL. The diameter of the medial and lateral condyles were measured on sagittal MRI images of these patients' knees.

Results: Subjects with ACL rupture had a highly statistically significantly shorter diameter of the lateral condyle as compared to their matched pairs from the control group $(p<0.01)$. Also, the lateral condyle of the subjects with ACL rupture had a significantly lesser diameter as compared to the medial condyle $(p<0.01)$, which was not the case in patients without ACL rupture $(p>0.05)$. Patients with intact ACL demonstrated significant indirect correlation of the diameter of both femoral condyles with the valgus angle of the lower leg $(p<0.01)$.

Conclusions: The shorter diameter of the lateral femoral condyle is connected with ACL rupture, both in women and men. The lack of correlation between the diameter of the femoral condyles and the valgus angle of the lower leg also represents a factor connected to ACL rupture.

\section{Introduction}

The morphometric parameters of the knee joint have often been associated with ACL (Anterior Cruciate Ligament) rupture $[1,2,3,4]$. The values of these parameters usually affect the biomechanics of the joint, i.e. their unfavorable values have been both theoretically and practically connected with the instability of the joint during activities involving jumping and rotation. Friden et al [5] drew attention to the configuration of the femoral condyles and their influence on the functional stability of the knee joint. In a study on 100 patients with ACL ruptures these authors demonstrated that patients with more rounded femoral condyles had a greater instability than the patients with ellipsoid shaped condyles. The medial femoral condyle has a larger surface than the lateral condyle, which contributes to a greater contact surface (1.6 times) [6], while the lateral condyle is somewhat longer.

The biomechanical properties of the knee joint entail movements around the transverse and vertical axis resulting in actual movements in the sagittal and horizontal planes. The knee joint flexes and extends around the transverse axis and it performs internal and external rotation around the vertical axis. These movements are not the same in the medial and lateral sections of the knee, neither when it comes to movements around the transverse nor around the vertical axis. During extension the lower leg performs additional internal rotation with its center in the medial tibial condyle, i.e. anterior tibial translation is greater on the lateral than on the medial condyle. As reported by Scott [7], the stability of the knee joint for 
each movement is regulated by two elements. The ligaments of the knee prevent translation if it is directed the same way as the fibers of the ligament, while rotation movements cannot be prevented by the ligaments alone; the activity of the muscles is also necessary for achieving stability. As the ACL is the primary stabilizer of anterior tibial translation [8], the factors increasing anterior tibial translation may additionally strain the ACL and lead to its rupture.

A discrepancy in size between the medial and lateral condyles of the femur may theoretically influence the mechanics of the knee in two ways, which coincide with the linear and angular movement taking place on the lateral tibial plateau during knee flexion. Linear gliding movement is represented by translation movements of the femoral condyles over the tibial plateau, while angular rolling movement, is represented by rotation movements of the femoral condyles. The third way that a disproportion in the sizes of the condyles may have effect is indirect. This is an increased valgus angle of the joint which can theoretically be the result of a smaller lateral femoral condyle.

Two hypotheses have been proposed in this paper: the decrease in the width of the lateral condyle, i.e. the decrease in the contact surface, results in the reduction of friction, which can consequently lead to increased anterior tibial translation and a greater strain on the ACL during extension. Additionally, the reduction in the diameter of the lateral condyle reduces the contact surface and reduces friction, which can also lead to increased anterior tibial translation and a greater strain on the ACL during extension.

The aim of this study is to determine the influence of the size of the medial and lateral condyles on ACL rupture.

\section{Methods}

The subjects and the control group for this prospective case study were individuals engaged in one of the sports activities entailing running, sudden changes in directions, jumping and landing and rotation movements (soccer, basketball, handball, volleyball, track and field). They were either professional or recreational athletes who had had workout sessions twice or more times a week prior to injury. These subjects were patients of the Clinic for orthopedic surgery and traumatology of the Clinical Center of Serbia. Their anamnesis stated noncontact knee injury, with or without ACL rupture. They were included in the present study voluntarily.

Two groups of subjects were formed: the experimental group and the control group. Each of the groups had 41 subjects. Matching between the groups was performed based on the type of sports activity, level of involvement (professional vs. recreational), gender, age (up to five years age difference within the pair) and side of the body. Due to the lateralization of the injuries, the right knee was examined in 18 clinical pairs (13 male and 5 female pairs) while the left knee was examined in 23 pairs ( 16 male and 7 female pairs). The youngest subjects in both groups were 16 years old at the time of data collection while the oldest subject in the examined group was 47 and in the control group 42 years old. Testing did not determine a statistically significant difference between the two groups as far as age is concerned $(p=n$. s.). 
Within the sample, 28 pairs (18 male and 9 female) were professional athletes while 13 pairs (10 male and 3 female) were recreational athletes who worked out regularly. The subjects from the control group trained 4.6 times a week, on average, while the subjects from the experimental group trained 4.3 times a week, on average. The distribution of the clinical groups, according to the type of sports activity, was as follows: 19 pairs of subjects were injured playing soccer, 7 pairs were injured playing basketball, 7 pairs were injured while training a track and field activity, 5 pairs were injured playing volleyball, while 3 pairs were injured playing handball.

Patients with osteal damage to the femoral condyle or with advanced degenerative changes in the knee joint were excluded from the study. Also, patients whose MRIs (Magnetic Resonance Imaging) were not taken in the neutral position of the lower limb were also excluded from the study. This limitation relates to the rotation of the lower leg, and verification was performed by comparing the posterior borders of the medial and lateral femoral and tibial condyles. Namely, the distance between the most posterior points of the lateral condyles could not vary by more than $3 \mathrm{~mm}$ from that same distance between the medial condyles (Fig. 1).

The following parameters related to the distal portion of the femur were monitored in the study: condyle width, condyle height and the radius of the condyle curvature. The condyle width was measured on a horizontal MRI image at the level of the popliteal sulcus (Fig. 2). The condyle height was measured on a frontal MRI image (the most anterior section not extending to the diaphysis of the bone, Fig. 3).

The curvatures of the medial and lateral condyles were measured on the distal portion of the femur. The sagittal image passing through the middle of the medial, i.e. lateral condyle was used to measure the vertical secant portion (a) and its height ( $h$ ), and, based on these values, the radius $(r)$ of the circle corresponding to the posterior convexity of the condyle (Fig. 4) was calculated with following formula:

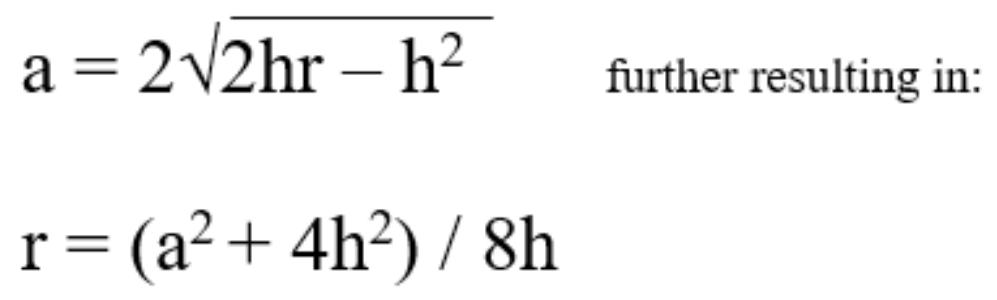

The angle between the upper and the lower leg (the valgus angle) was measured with a goniometer directly on the extremity of the subject. The differences in height, width and diameter size of the medial and lateral condyles between the experimental and the control group as well as the differences in diameter size between the medial and lateral condyles within each individual group were tested. The correlation between the condyle diameter and the valgus angle of the lower leg was also examined.

All of the data were processed with the SPSS 11.0 program. The differences between the two groups were tested with the Student's T-Test for paired samples, while the correlation was tested with the Pearson correlation coefficient in the SPSS 11.0 package. The level of statistical significance was set to 0.05 . 


\section{Results}

No statistically significant difference was determined in the dimensions of the condyle between the patients from the examined and those from the control group $(p=n$. s.), except in the case of the width of the lateral condyle $(p<0.05$; Table 1.).

Table 1

Condyle width and height values

\begin{tabular}{|llll|}
\hline & Control group & Experimental group & P value \\
\hline Width of medial condyle & $26.3 \pm 2.0$ & $26.7 \pm 2.3$ & n. s. \\
\hline Width of lateral condyle & $26.0 \pm 2.6$ & $27.3 \pm 2.7$ & 0.012 \\
\hline High of medial condyle & $42.2 \pm 4.6$ & $40.5 \pm 4.0$ & n. s. \\
\hline High of lateral condyle & $40.9 \pm 5.0$ & $40.3 \pm 3.8$ & n. s. \\
\hline
\end{tabular}

The T-Test for paired samples showed a highly statistically significant difference between the experimental and the control group regarding the lateral condyle radius $(p<0.01)$, which was not the case with the medial condyle radius $(p=n$. s.). Such a distribution of statistical significance was confirmed both within the male subgroup (lateral condyle radius: $p<0.05$; medial condyle radius: $p=n$. $s$.) as well as within the female subgroup (lateral condyle radius: $p<0.05$; medial condyle radius: $p=n$. s.; Table 2 .). Also, the experimental group of subjects had a smaller diameter of the lateral femoral condyle than the diameter of the medial femoral condyle, which was not the case with the patients from the control group (Table 3.).

Table 2

Radius of the medial and lateral femoral condyles $(\mathrm{mm})$

\begin{tabular}{|lllll|}
\hline & Condyles & Control group & Experimental group & Statistical significance \\
\hline $\begin{array}{l}\text { Entire } \\
\text { population }\end{array}$ & Lateral condyle & $20.3 \pm 2.9$ & $18.8 \pm 2.1$ & $\mathrm{p}=0.004$ \\
\cline { 2 - 5 } & Medial condyle & $20.0 \pm 2.3$ & $19.9 \pm 2.0$ & n. s. \\
\multirow{2}{*}{ Men } & Lateral condyle & $21.0 \pm 2.8$ & $19.7 \pm 1.6$ & $\mathrm{p}=0.039$ \\
\cline { 2 - 4 } & Medial condyle & $20.7 \pm 2.3$ & $20.5 \pm 1.9$ & n. s. \\
& Lateral condyle & $18.5 \pm 2.3$ & $16.7 \pm 1.3$ & $\mathrm{p}=0.026$ \\
& Medial condyle & $18.6 \pm 1.9$ & $18.5 \pm 1.7$ & n. s. \\
\hline
\end{tabular}


Table 3

Statistical significance ( $p$ value) of the difference in diameter between the medial and lateral condyles within each individual group

\begin{tabular}{|llll|}
\hline Subject group & Mixed population & Men & Women \\
\hline Experimental & 0.001 & 0.046 & 0.000 \\
\hline Control & 0.491 & 0.370 & 0.870 \\
\hline
\end{tabular}

A statistically significant difference of the lower leg valgus angle measurements between the experimental and control group was not established. $(p=n$. s.). Subjects with ACL rupture were noted to have the value for this angle of $6.2^{\circ}$, while subjects with an intact ACL had an angle of $6.0^{\circ}$. However, the diameter of the lateral and medial condyles of the patients with intact ACL demonstrated a significant reverse correlation with the valgus angle of the lower leg $(p<0.01 ; r=-0.503 ; r=-0.454$; respectively, Fig. 3$)$. On the other hand, the diameter of the medial and lateral condyles of patients with ACL ruptures did not demonstrate significant correlation $(p>0.05 ; r=0.081 ; r=-0.035$; respectively, Fig. 4).

\section{Discussion}

The most important discovery of the present study confirmed the second initial hypothesis that a smaller radius of the lateral condyle is connected with anterior cruciate ligament rupture. The mechanism itself can be theoretically explained by the fact that a condyle of a lesser diameter has a smaller contact surface with the lateral tibial plateau and can therefore theoretically more easily slide backwards, thus straining the ACL to a greater extent. Additionally, the introductory theoretical observation that anterior tibial translation is greater when the lateral femoral condyle is of a smaller diameter, should also be taken into consideration. This can empirically be substantiated, in a simplified manner, by the rolling motion of two wheels of different diameter on one axis, with the smaller wheel always falling behind. If this model is adjusted to the knee joint with a lesser diameter of the lateral condyle, this means that with every movement of extension, when the femoral condyles are moving forward across the tibial plateau, the lateral condyle will fall behind, the lower leg will remain in internal rotation, which will additionally strain the ACL.

Within the experimental group (and its different sex subgroups) the radius of the medial condyle was significantly greater than the radius of the lateral condyle (men: $p<0.05$; women: $p<0.01$ ), which was not the case with the control group. Looking at the tables it becomes apparent that within both gender subgroups, the radius of the lateral condyle of the patients with ACL rupture is shorter by about 1 to 2 millimeters than the radius of the same condyle in the control group and shorter than the radius of the medial condyle of both the experimental and the control group. Results very similar to those of the present study were obtained by Li et al [9] who monitored the differences between the sexes in relation to the radius of the femoral condyles by means of computer analysis. They established a highly statistically 
significant difference $(p<0.01)$ between men and women $(20.3: 18.0 \mathrm{~mm})$ but did not find a difference in the radii of the medial and lateral condyles (19.3:19.4 mm), which also coincides with the findings in the control group for the present study. (The subjects in the study conducted by Li et al did not have ACL rupture.).

In their extensive study of morphometric characteristics of the femur and tibia performed on skeletal remains of 143 individuals, Harrington et al [10] established that there was no significant difference regarding the sagittal diameter between people of a different sex, belonging to a different age group, or with a different nutritional status (obesity). Monk et al [11] measured the curvature of the femoral condyles in the frontal sagittal plane on MRI images of 35 healthy volunteers. The length of the sagittal diameter of the posterior portion of the medial condyle measured $21 \mathrm{~mm}$ and did not significantly differ from the same measurement on the lateral condyle, nor from the curvature of the distal portion of the medial condyle in the frontal plane. These measurements are approximately the same as the measurements from the present study. Elias et al [12] also measured similar dimensions of the medial condyle radius $(21 \mathrm{~mm})$ in their study on 16 radiographically analyzed knees.

By means of geometric analysis performed with the help of a three-dimensional laser scanner, Kosel et al [13] measured the radius of the posterior portion of the femoral condyles on 16 cadaveric knees. Their results point to statistically significantly greater values $(p<0.001)$ of the lateral condyle radius $(20.3 \mathrm{~mm})$ than the radius of the medial condyle $(18.7 \mathrm{~mm})$. This is the only study where the dimensions of the lateral condyle radius were greater than those for the medial condyle radius. Using radiographic images, Hollister et al [14] measured a $22.8 \mathrm{~mm}$ radius of the medial condyle. Using radiographic images of Japanese subjects without osteal or joint pathology, Asano et al [15] measured the medial condyle radius of $26 \mathrm{~mm}$, and a lateral condyle radius of $22.8 \mathrm{~mm}$. Bearing in mind that radiographic images have an enlargement of approximately $10 \%$, one could say that these results support the results of the present study.

The length of the diameter of the medial and lateral femoral condyles in patients with an intact ACL demonstrated an indirect link with the valgus angle of the lower leg. In other words, a proportionally smaller medial and lateral femoral condyle had impact on the increased valgisation of the lower leg. Such a proportion can conditionally be understood to represent a protective mechanism, as it is found in patients without $\mathrm{ACL}$ rupture. On the other hand, an absence in correlation between the diameter of the medial and lateral femoral condyle on one hand, and the valgus angle of the lower leg on the other hand, is a feature of a knee with ACL rupture.

Theoretically speaking, one of the reasons for the lack of correlation between the condyle diameter and the valgus angle within the examined group, could be the ellipsoid shape of the condyle in the anteriorposterior or proximal-distal directions. Namely, the condyle diameter was obtained on the basis of the secant portion of the condyle which is in contact with the tibia during flexion, while the valgus angle was measured, as always, in extension. Within the control group, however, a correlation was established between the valgus angle and diameter of the condyle, leading to the conclusion that the femoral 
condyles have equal curvatures in both the directions monitored. The ellipsoid shape of the femoral condyles in patients with a ruptured ACL explains the lack of correlation between the valgus angle and the condyle diameter, but could also speak in favor of greater strain placed on the ACL in the process of transition from flexion to extension (and vice versa), since in transition from a larger diameter of the ellipsis to a smaller one, the movement of gliding over the tibial plateau would be favored, thus leading to abrupt anterior tibial translation and strain on the ACL.

\section{Conclusion}

A smaller diameter of the lateral femoral condyle is connected to ACL rupture, both in men and women. The mechanism which brings about this rupture is probably represented by the favoring of anterior tibial translation on the lateral condyle and a consequently greater medial rotation of the lower leg in flexion, which puts an increased strain on the ACL. The lack of correlation of the diameter of the femoral condyles with the valgus angle of the lower leg also represents a factor connected to ACL rupture.

\section{Abbreviations}

ACL - Anterior Cruciate Ligament

MRI - Magnetic Resonance Imaging

\section{Declarations}

All sections are relevant to the manuscript.

\section{Fundings}

The study has not been financially supported.

- The authors did not receive support from any organization for the submitted work.

- No funding was received to assist with the preparation of this manuscript.

- No funding was received for conducting this study.

- No funds, grants, or other support was received.

\section{Conflict of interest/Competing interest}

Authors declare no any conflict of interest.

\section{Availability of data and material}


The authors agree with the transparency of data and materials.

\section{Code availability}

This paper is not in the field of computing, related field or interdisciplinary field

\section{Authors' contributions}

All authors contributed to the study conception and design. Material preparation, data collection and analysis were performed by [Lazar Stijak], [Marko Kadija], [Darko Milovanović], [Ninoslav Begović] and [Dubravka Aleksić]. The first draft of the manuscript was written by [Lazar Stijak], [Darko Milovanović], [Vuk Djulejić], [Ana Starčević] and [Marko Bumbaširević]. All authors commented on previous versions of the manuscript. All authors read and approved the final manuscript.

\section{Consent to participate}

All participants agree to participate in the study.*

\section{Consent for publication}

All participants agree to the publication of the data.*

* The condition for the ethical approval of our faculty (School of Medicine, University of Belgrade) is the consent of the participants with the publication of the data and participation in the study.

\section{References}

1. Simon RA, Everhart JS, Nagaraja HN, Chaudhari AM. A case-control study of anterior cruciate ligament volume, tibial plateau slopes and intercondylar notch dimensions in ACL-injured knees. J Biomech. 2010;18(9):1702-7. 43(.

2. Souryal TO, Moore HA, Evans JP. Bilaterality in anterior cruciate ligament injuries: associated intercondylar notch stenosis. Am J Sports Med. 1998;16:449-54.

3. Stijak L, Herzog RF, Schai P. Is there an influence of the tibial slope of the lateral condyle on the ACL lesion? A case-control study. Knee Surg Sports Traumatol Arthrosc. 2008;16(2):112-7.

4. Stijak L, Radonjić V, Nikolić V, Blagojević Z, Herzog RF. The position of anterior cruciate ligament in frontal and sagittal plane and its relation with the inner side of the lateral femoral condyle. Knee Surg Sports Traumatol Arthrosc. 2009;17(8):887-94.

5. Fridén $T$, Jonsson A, Erlandsson $T$, Jonsson $K$, Lindstrand A. Effect of femoral condyle configuration on disability after an anterior cruciate ligament rupture. 100 patients followed for 5 years. Acta 
Orthop Scand. 1993;65(5):571-4.

6. Murshed AM, Cicekcibasi AE, Karabacakoglu A, Seker M, Ziylan T. Distal femur morphometry: a gender and bilateral comparative study using magnetic resonance imaging. Surg Radiol Anat. 2005;27(2):108-12.

7. Scott NW. Ligament and Extensor Mechanism Injuries of the Knee, diagnosis and treatment. St. Louis: Mosby Year Book; 1991.

8. Hseih $\mathrm{H}$, Walker SP. Stabilizing Mechanism of the Loaded and Unloaded Knee Joint. J Bone Joint Surg Am. 1976;58(1):87-93.

9. Li K, Langdale E, Tashman S, Harner C, Zhang X. Gender and condylar differences in distal femur morphometry clarified by automated computer analyses. J Orthop Res. 2012;30(5):686-92.

10. Harrington IK, Wescott JD. Size and shape differences in the distal femur and proximal tibia between normal weight and obese American whites. J Forensic Sci. 2015;60(Suppl 1):32-8.

11. Monk AP, Choji K, O'Connor JJ, Goodfellow JW, Murray DW. The shape of the distal femur: a geometrical study using MRI. Bone Joint J. 2014;96-B(12):1623-30.

12. Elias SG, Freeman MA, Gokcay El. A correlative study of the geometry and anatomy of the distal femur. Clin Orthop Relat Res. 1990;260:98-103.

13. Kosel J, Giouroudi I, Scheffer C, Dillon E, Erasmus P. Anatomical study of the radius and center of curvature of the distal femoral condyle. J Biomech Eng. 2010;132(9):091002.

14. Hollister MA, Jatana S, Singh KA, Sullivan WW, Lupichuk GA. A correlative study of the geometry and anatomy of the distal femur. Clin Orthop Relat Res. 1993;290:259-68.

15. Asano T, Akagi M, Nakamura T. The functional flexion-extension axis of the knee corresponds to the surgical epicondylar axis: in vivo analysis using a biplanar image-matching technique. $\mathrm{J}$ Arthroplasty. 2005;20(8):1060-7.

\section{Figures}



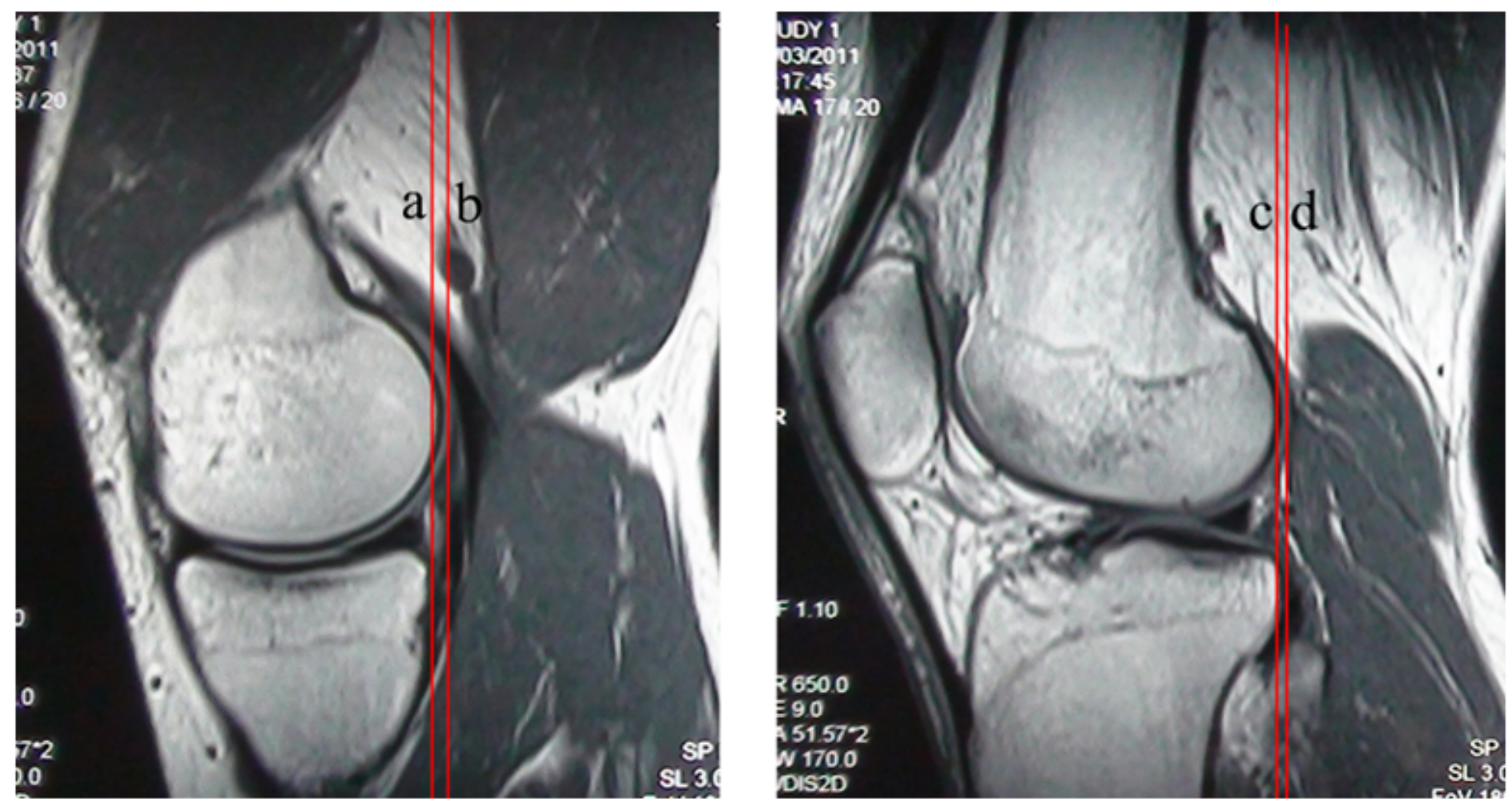

\section{Figure 1}

Verification of lower leg rotation performed by comparing the posterior borders of the medial and lateral femoral and tibial condyles (to the left is the medial and to the right the lateral condyle.) The distance between $a$ and $b$ lines could not vary by more than $3 \mathrm{~mm}$ from the distance between lines $c$ and $d$. 


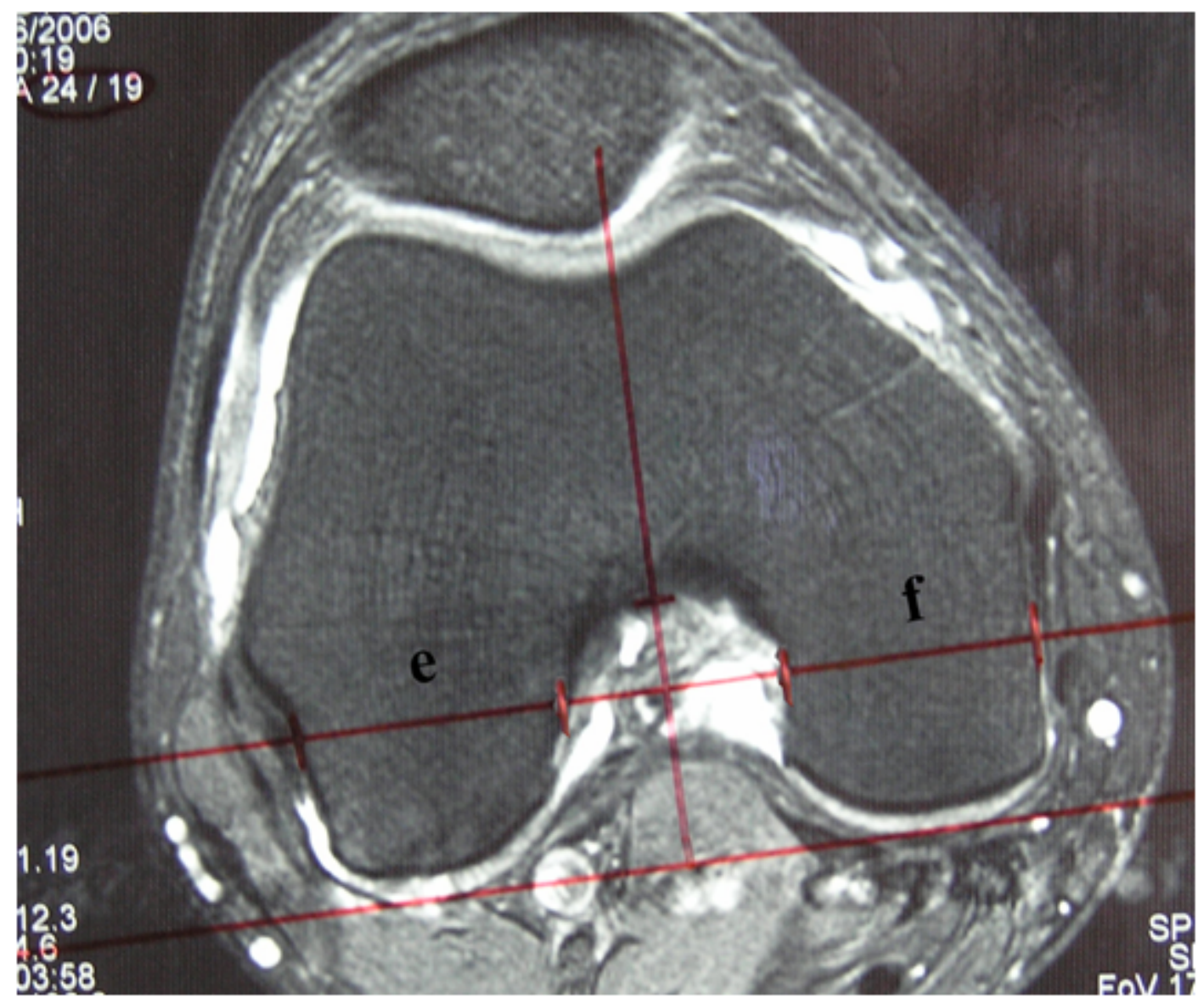

Figure 2

Measuring the width of the lateral condyle (e) and medial condyle (f) at the level of the popliteal sulcus on a horizontal MRI image 


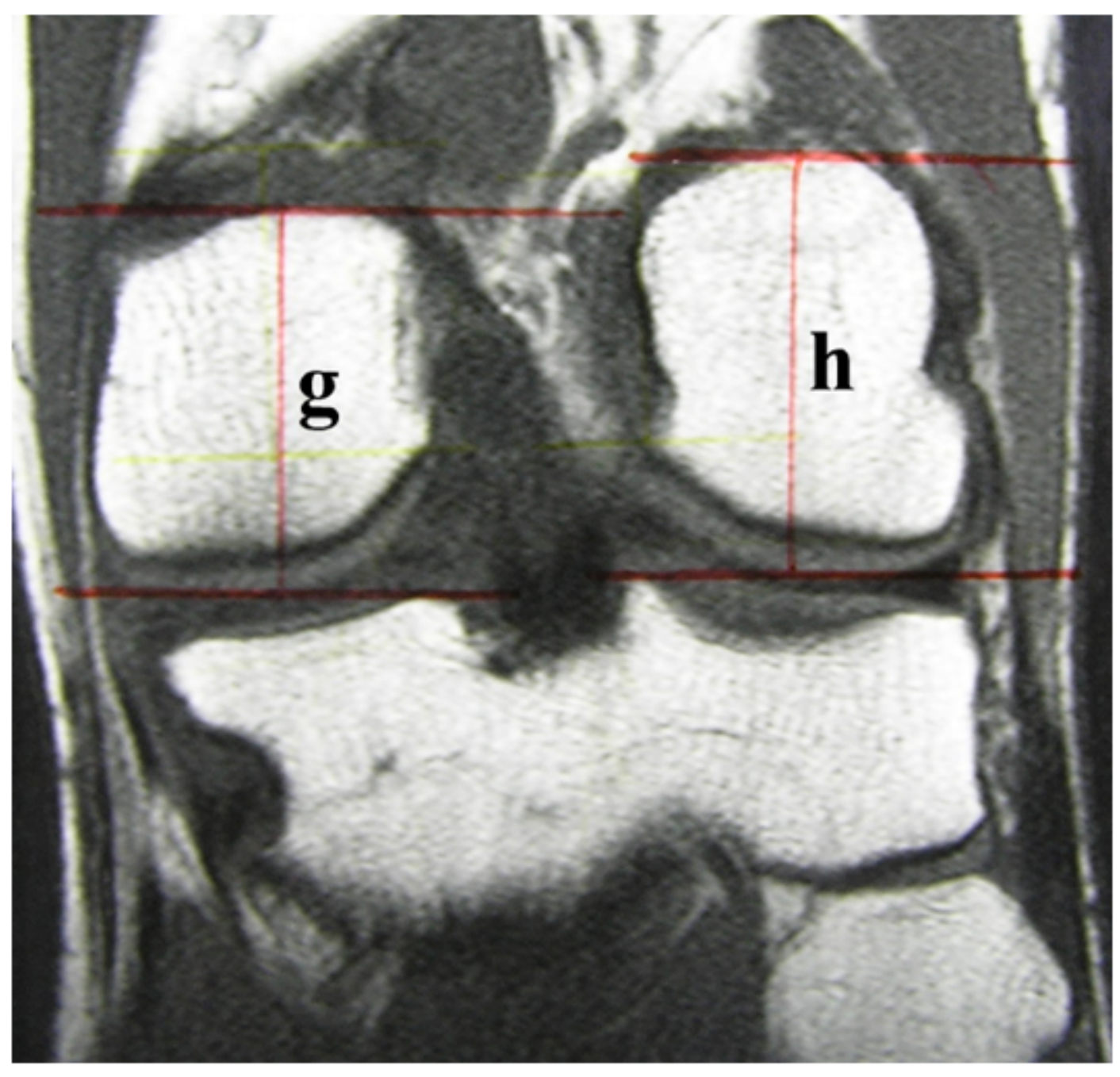

Figure 3

Measuring the height of the medial condyle $(\mathrm{g})$ and lateral condyle $(\mathrm{h})$ on a frontal MRI image 


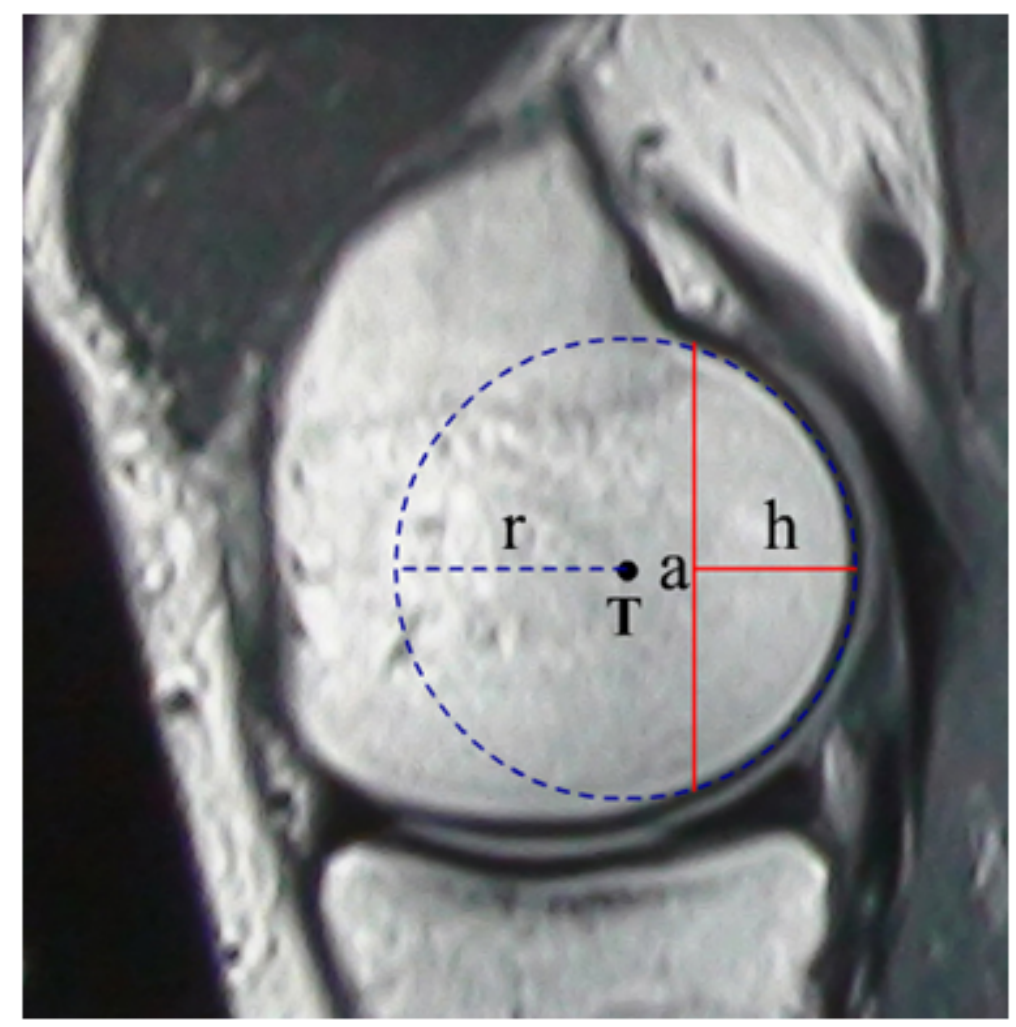

Figure 4

Measurement of the vertical secant portion and its height on the femoral condyle. Line a represents the secant portion of the circle, and line $h$ represents its height. The radius is marked with $r$. 


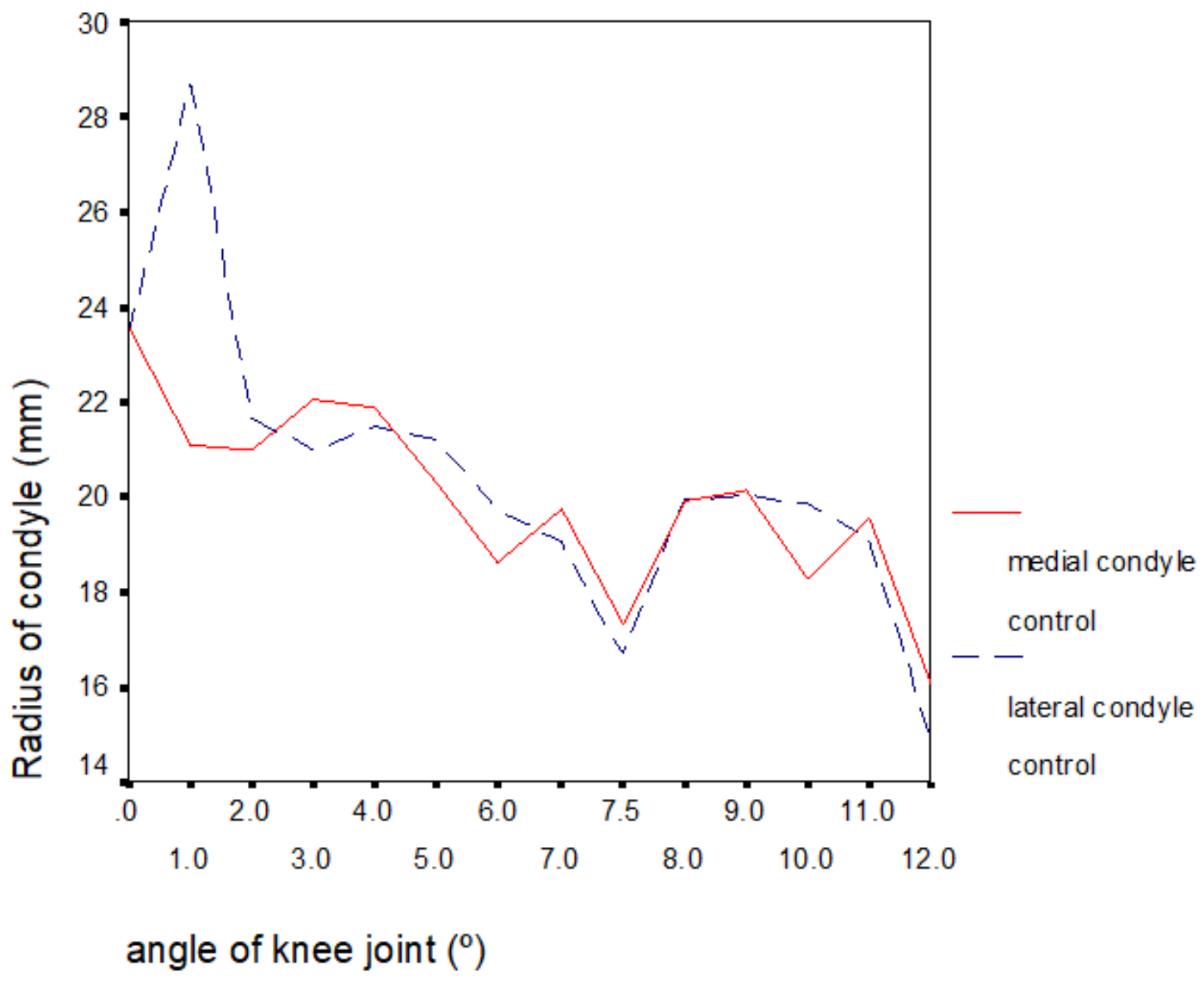

Figure 5

Correlation of the diameter of the medial and lateral condyles with the valgus angle of the lower leg within the control group. 


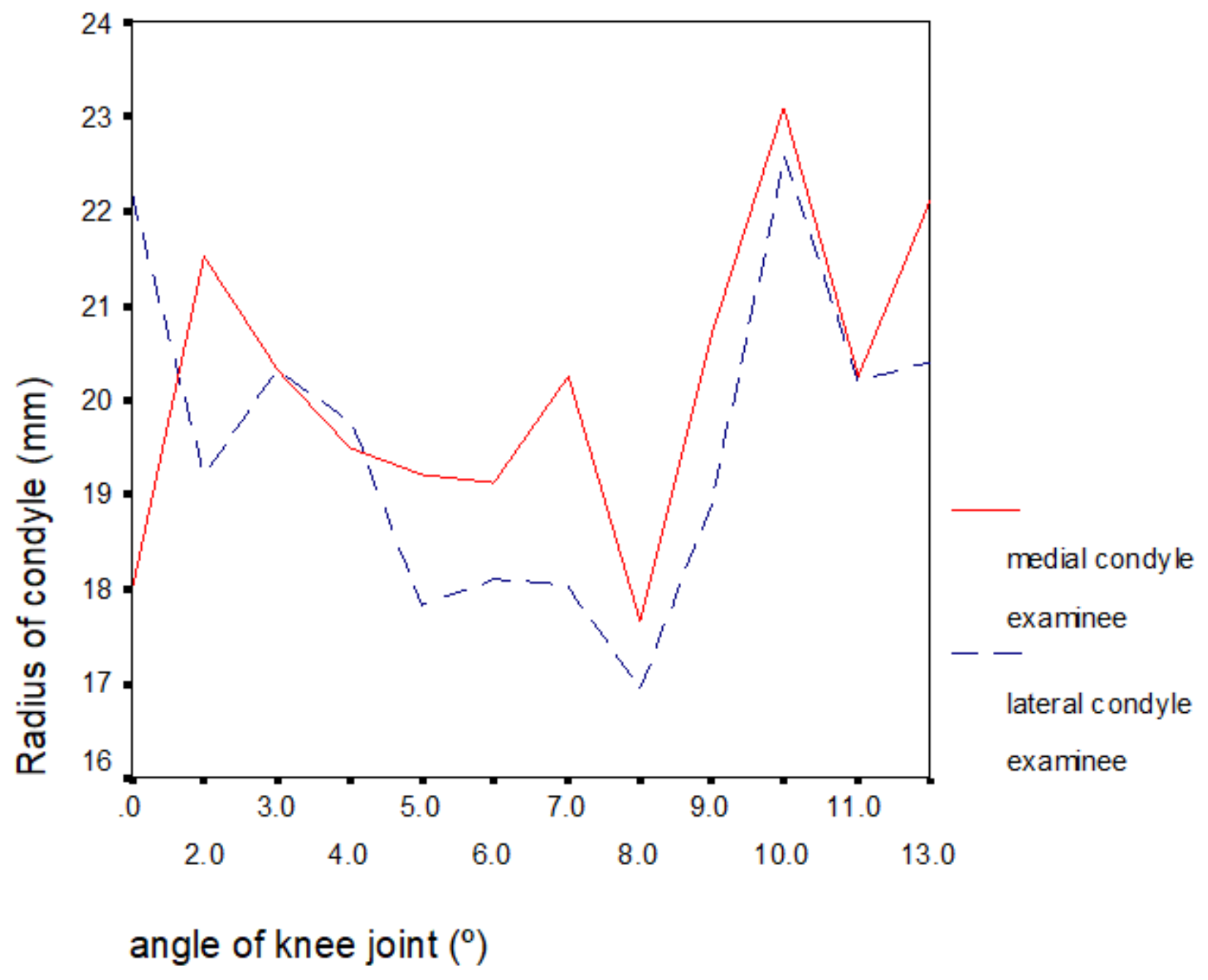

Figure 6

Correlation of the diameter of the medial and lateral condyles with the valgus angle of the lower leg within the experimental group.

\section{Supplementary Files}

This is a list of supplementary files associated with this preprint. Click to download.

- datacondyles.sav 